\title{
TLE1 expression is not specific for synovial sarcoma: a whole section study of 163 soft tissue and bone neoplasms
}

\author{
Kemal Kosemehmetoglu ${ }^{1}$, Julie A Vrana ${ }^{2}$ and Andrew L Folpe ${ }^{2}$ \\ ${ }^{1}$ Department of Pathology, Hacettepe University Faculty of Medicine, Ankara, Turkey and ${ }^{2}$ Department of \\ Laboratory Medicine and Pathology, Mayo Clinic, Rochester, MN, USA
}

\begin{abstract}
TLE1, a transcriptional repressor essential in hematopoiesis, neuronal differentiation and terminal epithelial differentiation, has recently been shown in a single tissue microarray study to be a highly sensitive and relatively specific marker of synovial sarcomas. Expression of TLE1 has not, however, been studied in standard sections of soft tissue and bone tumors. We investigated TLE1 expression in a large series of well-characterized mesenchymal tumors, to more fully characterize the range of TLE1 expression. Standard sections of 163 bone and soft tissue tumors were immunostained for TLE1 (sc-9121, 1:100; Santa Cruz Biochemicals) using the Dako Dual Envision + detection system. Nuclear positivity was scored as negative ( $<5 \%$ of cell positive), $1+(5-25 \%$ of cells positive), $2+(25-50 \%$ of cells positive), and $3+(>50 \%$ of cells positive). Overall, TLE1 was expressed by 18 of $20(90 \%)$ of synovial sarcoma, with 16 cases $(89 \%)$ showing 2-3 + positivity. However, TLE1 expression was also seen in 53 of $143(37 \%)$ non-synovial sarcoma, with 36 such cases $(25 \%)$ showing $2-3$ + positivity. TLE1 expression was commonly seen in peripheral nerve sheath tumors, including $33 \%$ of neurofibromas, $100 \%$ of schwannomas, and $30 \%$ of malignant peripheral nerve sheath tumors. Among non-neoplastic tissues, nuclear TLE1 expression was variably present in basal keratinocytes, adipocytes, perineurial cells, endothelial cells and mesothelial cells. Our study confirms the excellent sensitivity of TLE1 for synovial sarcoma. However, TLE1 expression is by no means specific for synovial sarcoma, being present in a number of tumors, which enter its differential diagnosis, in particular tumors of peripheral nerve sheath origin. Heterogeneity of TLE1 expression likely explains the differences between the present standard section study and the earlier TMA study. TLE1 may be of value in the differential diagnosis of synovial sarcoma, but should be used only in the context of a panel of antibodies. Morphology, ancillary immunohistochemistry for traditional markers such as cytokeratins and CD34, and molecular confirmation of synovial sarcoma-associated fusion genes should remain the 'gold standards' for this diagnosis.
\end{abstract}

Modern Pathology (2009) 22, 872-878; doi:10.1038/modpathol.2009.47; published online 10 April 2009

Keywords: synovial sarcoma; TLE1; immunohistochemistry; sarcoma; molecular diagnostics

Synovial sarcoma is one of the most common sarcomas in adults, accounting for $6-10 \%$ of all soft tissue sarcomas. ${ }^{1,2}$ Approximately $70 \%$ of synovial sarcoma are of the monophasic fibrous subtype and $30 \%$ are biphasic, showing both spindle cell and glandular differentiation., ${ }^{1,2}$ Poorly differentiated synovial sarcomas, showing a round cell pattern, account for $<5 \%$ of synovial sarcoma, and may arise from either monophasic or biphasic synovial sarcomas. ${ }^{3-5}$ Although the recognition of biphasic syno-

Correspondence: Dr AL Folpe, MD, Department of Laboratory Medicine and Pathology, Mayo Clinic, 200 SW, Rochester, MN 55905, USA.

E-mail: Folpe.Andrew@Mayo.edu

Received 10 February 2009; revised 12 March 2009; accepted 16 March 2009; published online 10 April 2009 vial sarcoma is typically straightforward, not requiring ancillary immunostains or molecular genetic tests, the differential diagnosis of monophasic and poorly differentiated synovial sarcoma may be more challenging. Although immunohistochemistry for markers such as cytokeratins, S100 protein, CD34, smooth muscle actin and desmin plays a valuable role in this differential diagnosis, there is overlap in the immunophenotypes of these various tumors, and a definitive diagnosis is not always possible with immunohistochemistry alone. Although molecular diagnostic methods such as reverse transcriptase polymerase chain reaction and fluorescent in situ hybridization to detect the synovial sarcoma-specific $\mathrm{t}(\mathrm{X} ; 18)(S S 18-S S X 1-2)$ are increasingly used for the definitive diagnosis of synovial sarcoma, these techniques are not yet 
available in all laboratories, and require wellpreserved genetic material. Thus there has been continued interest in the development of novel immunohistochemical markers for the diagnosis of synovial sarcoma.

Transducin-like enhancer of split 1 (TLE1), one of four members of the TLE gene family encoding transcriptional corepressors homologous to the Drosophila groucho gene, is involved in control of hematopoiesis, neuronal differentiation and terminal epithelial differentiation. ${ }^{6-8}$ TLE1 also plays an important role in the $\mathrm{Wnt} / \beta$-catenin signaling pathway, where TLE1 protein competes with and displaces $\beta$-catenin, producing TLE1-TCT/LEF complexes that repress transcription. ${ }^{9-11}$ The Wnt/ $\beta$-catenin signaling pathway is known to be associated with synovial sarcoma, ${ }^{12-14}$ and TLE1 has been shown in a variety of DNA microarray studies to be consistently expressed in synovial sarcomas. ${ }^{12,14,15}$ Most recently, using tissue microarrays, Terry et $a l^{16}$ have shown TLE1 protein expression to be a sensitive and relatively specific marker of synovial sarcoma in formalin-fixed, paraffinembedded tissues. However, the sensitivity and specificity of TLE1 have not yet been tested in standard, full-sized tissue sections.

\section{Materials and methods}

Standard whole sections of 163 formalin-fixed, paraffin-embedded bone and soft tissue tumors were immunostained for TLE1 (sc-9121, 1:100; Santa Cruz Biochemicals, Santa Cruz, CA, USA) with Dako
Background Reducing Diluent, pretreatment in the Dako PTLink module with EDTA pH 8.0 for thirty minutes at $97^{\circ} \mathrm{C}$, and Dako Dual Envision + detection with Dako DAB + chromogen (Dako Corp, Carpinteria, CA, USA). All available histological and immunohistochemical studies were re-reviewed by two of the authors (KK and ALF) and the diagnoses confirmed. Prior confirmation of the presence of the $t(X ; 18)$ had been performed in 12-15 monophasic or poorly differentiated synovial sarcomas; the remaining cases were morphologically appropriate, contained scattered cytokeratin-positive cells and were CD34-negative. Only malignant peripheral nerve sheath tumors ${ }^{1}$ displaying pleomorphism considerably beyond that seen in synovial sarcomas and lacking cytokeratin expression, or $^{2}$ arising in patients with known neurofibromatosis type 1 , were included in this study. The tumor subtypes are listed in Table 1. TLE1 expression was scored as 'negative' ( $<5 \%$ of cell positive), ' $1+$ ' (5-25\% of cells positive), ' $2+$ ' $(25-50 \%$ of cells positive) and ' $3+$ ' ( $>50 \%$ of cells positive). Only nuclear staining was considered to represent true TLE1 expression. A genetically confirmed monophasic synovial sarcoma with known $3+$ TLE1 expression was used as a positive control; negative controls consisted of substitution of buffer for the primary antibody.

\section{Results}

The results are summarized in Table 1. Overall, TLE1 was expressed by 18 of $20(90 \%)$ of synovial

Table 1 Immunohistochemical results

\begin{tabular}{|c|c|c|c|c|c|c|c|}
\hline Diagnosis & $\mathrm{N}$ & Negative & $1+$ & $2+$ & $3+$ & $2-3+(\%)$ & Any positive (\%) \\
\hline Alveolar soft part sarcoma & 2 & 2 & 0 & 0 & 0 & 0 & 0 \\
\hline Acral myxoinflammatory fibroblastic sarcoma & 1 & 0 & 0 & 1 & 0 & 100 & 100 \\
\hline Chordoma & 10 & 9 & 1 & 0 & 0 & 0 & 10 \\
\hline Clear cell sarcoma & 1 & 1 & 0 & 0 & 0 & 0 & 0 \\
\hline Desmoplastic small round cell tumor & 1 & 1 & 0 & 0 & 0 & 0 & 0 \\
\hline Endometrial stromal sarcoma & 3 & 0 & 1 & 0 & 2 & 66 & 100 \\
\hline Epithelioid sarcoma & 6 & 4 & 0 & 1 & 1 & 33 & 33 \\
\hline Ewing sarcoma & 4 & 4 & 0 & 0 & 0 & 0 & 0 \\
\hline Fibrosarcoma & 3 & 3 & 0 & 0 & 0 & 0 & 0 \\
\hline Fibroma & 2 & 2 & 0 & 0 & 0 & 0 & 0 \\
\hline Gastrointestinal stromal tumor & 6 & 6 & 0 & 0 & 0 & 0 & 0 \\
\hline Leiomyosarcoma & 5 & 4 & 0 & 1 & 0 & 20 & 20 \\
\hline Liposarcoma & 24 & 12 & 5 & 4 & 3 & 29 & 50 \\
\hline Low-grade fibromyxoid Sarcoma & 1 & 1 & 0 & 0 & 0 & 0 & 0 \\
\hline Lipoma & 8 & 5 & 2 & 1 & 0 & 13 & 38 \\
\hline Malignant peripheral nerve sheath tumor & 10 & 4 & 3 & 0 & 3 & 30 & 30 \\
\hline Myxofibrosarcoma & 3 & 2 & 1 & 0 & 0 & 0 & 33 \\
\hline Neurofibroma & 9 & 6 & 1 & 2 & 0 & 22 & 33 \\
\hline Parachordoma/myoepithelioma & 3 & 3 & 0 & 0 & 0 & 0 & 0 \\
\hline Rhabdomyosarcoma & 13 & 8 & 0 & 2 & 3 & 39 & 39 \\
\hline Schwannoma & 11 & 0 & 2 & 6 & 3 & 82 & 100 \\
\hline Solitary fibrous tumor & 5 & 3 & 1 & 0 & 1 & 20 & 40 \\
\hline Synovial sarcoma & 20 & 2 & 1 & 1 & 16 & 85 & 90 \\
\hline Undifferentiated pleomorphic sarcoma & 12 & 10 & 0 & 1 & 1 & 17 & 17 \\
\hline Total & 163 & 92 & 18 & 20 & 33 & 32 & 43 \\
\hline
\end{tabular}


874
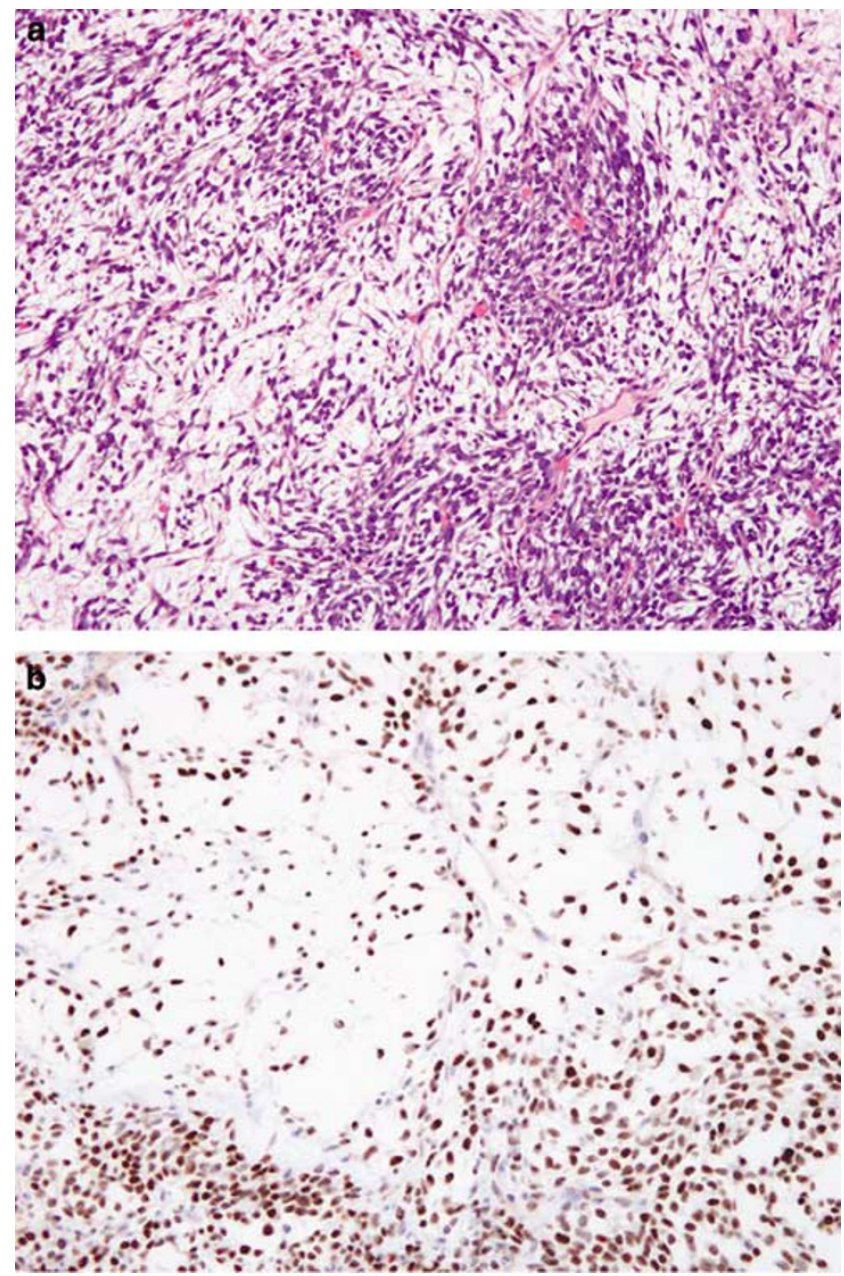

Figure 1 Monophasic synovial sarcoma with myxoid change (a), positive for TLE1 expression in both myxoid and non-myxoid areas (b).

sarcoma, with 17 cases (85\%) showing 2-3+ positivity (Figures 1-3). However, TLE1 expression was also seen in 53 of $143(37 \%)$ non-synovial sarcoma, with 36 such cases (25\%) showing $2-3+$ positivity. TLE1 expression was commonly seen in peripheral nerve sheath tumors, including 30\% of malignant peripheral nerve sheath tumors (Figures 4 and 5), $100 \%$ of schwannomas (Figure 6) and $33 \%$ of neurofibromas. Figures 7 and 8 illustrate TLE1 expression in other non-synovial sarcomas (alveolar rhabdomyosarcoma and myxoid liposarcoma). In TLE1-positive non-synovial sarcomas expression was often heterogenous, with some fields showing near uniform positivity, and others showing only patchy or even absent positivity. The overall sensitivity and specificity of TLE1 expression for the diagnosis of synovial sarcoma was 85 and $75 \%$, respectively. Among non-neoplastic tissues, nuclear TLE1 expression was occasionally present in basal keratinocytes, adipocytes, perineurial cells, endothelial cells and mesothelial cells.
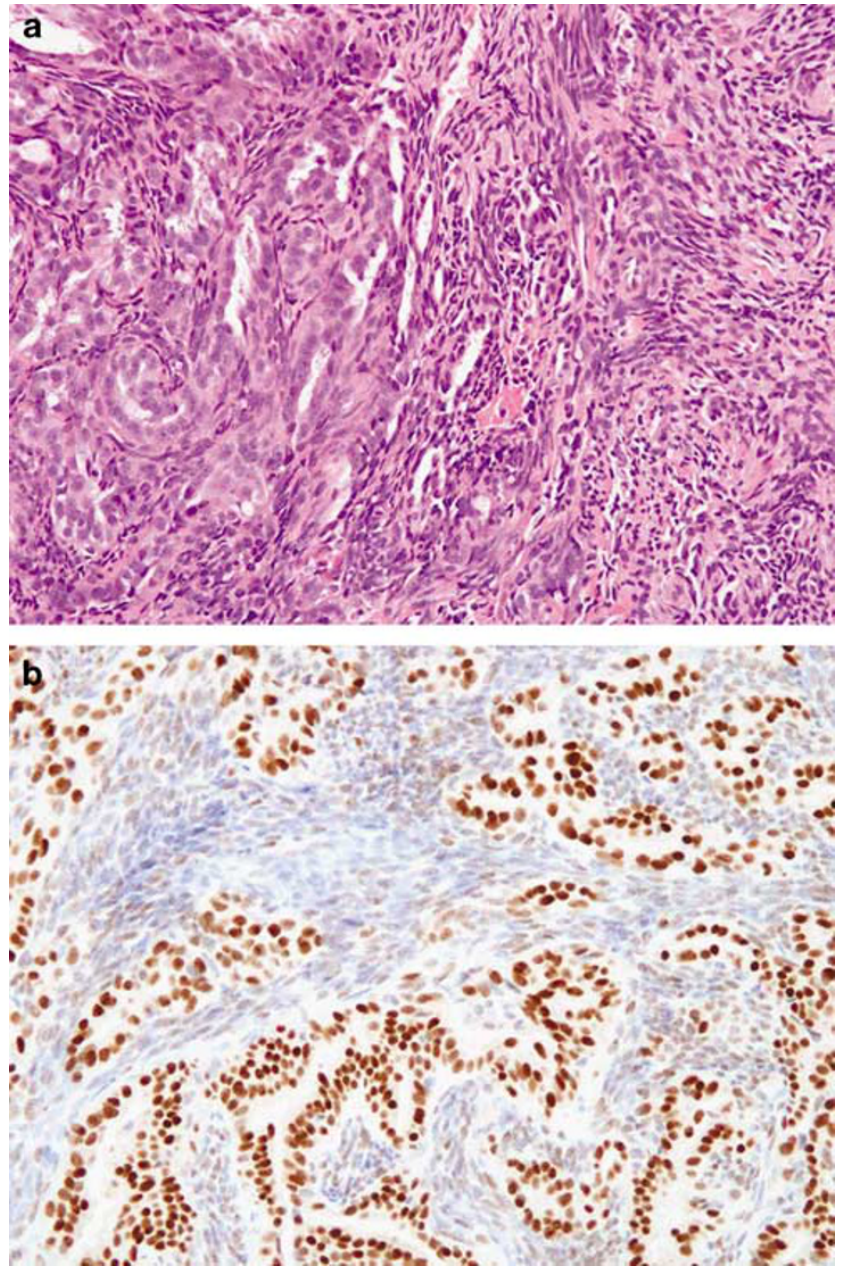

Figure 2 Biphasic synovial sarcoma (a) with $3+$ TLE1 expression in glandular epithelium (b). TLE1 expression is much less frequent in the spindled component of this biphasic tumor.

\section{Discussion}

In this study, the first whole section study of TLE1 expression in mesenchymal tumors, we have confirmed and expanded on the previous work of Terry et al. ${ }^{16}$ In agreement with this earlier tissue microarray study, we have found TLE1 to be a highly sensitive marker of synovial sarcoma, present in close to $90 \%$ of cases, typically in $>50 \%$ of cells. However, we have found TLE1 expression in a somewhat higher percentage of tumors that may enter the differential diagnosis of synovial sarcoma than has previously been reported, with $2-3+$ positivity seen in our study in $20 \%$ of solitary fibrous tumors/hemangiopericytomas, $82 \%$ of schwannomas, $39 \%$ of rhabdomyosarcomas, $22 \%$ of neurofibromas and $30 \%$ of malignant peripheral nerve sheath tumors, as compared with $30,27,0$, 0 and $5 \%$, respectively, in the study of Terry et al. We have also found 2-3 + TLE1 expression in a minority of other mesenchymal tumors (which 

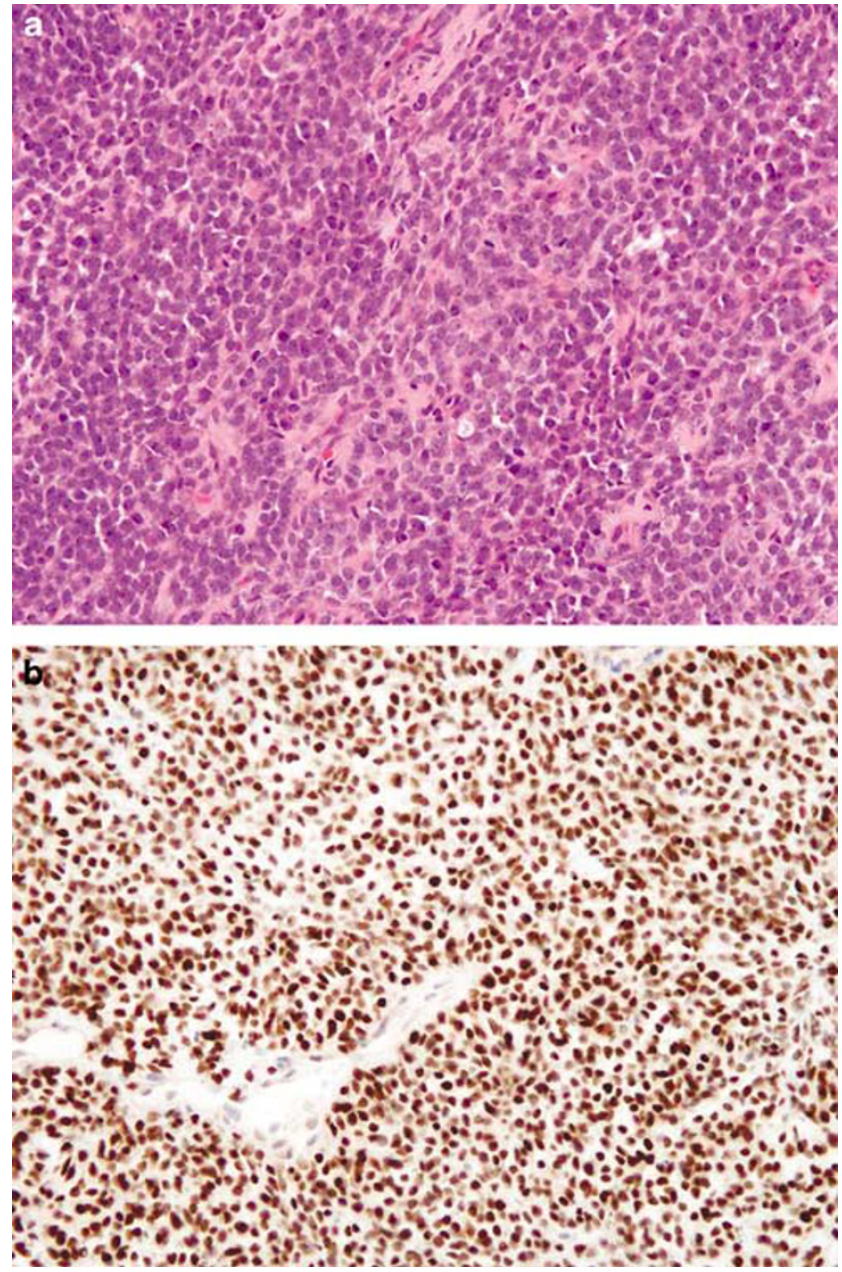

Figure 3 Poorly differentiated synovial sarcoma (a) with $3+$ TLE1 expression (b).

would not typically enter the differential diagnosis of synovial sarcoma) including endometrial stromal sarcoma, leiomyosarcoma, lipoma/liposarcoma and undifferentiated pleomorphic sarcoma (so-called 'malignant fibrous histiocytoma'), indicating that TLE1 expression may be more widespread than has been previously recognized.

The differences between our results and those of Terry and co-workers may be explained by our use of whole sections, as opposed to tissue microarrays, inasmuch as TLE1 expression may vary from area to area within a given tumor. It is likely that our use of larger tissue sections resulted in a greater number of ' $2+$ ' cases, as compared with the study of Terry et al, in which such cases might have been scored as ' $1+$ ' or even negative. Validation of this hypothesis would require whole section study of cases from this earlier study. It is unlikely that the immunohistochemical methods used in this study account for these differences, as our study used the same polyclonal TLE1 antibody as Terry et al, at a higher dilution (1:100 vs 1:20). It is possible that the Dako Envision + detection system used in this study is
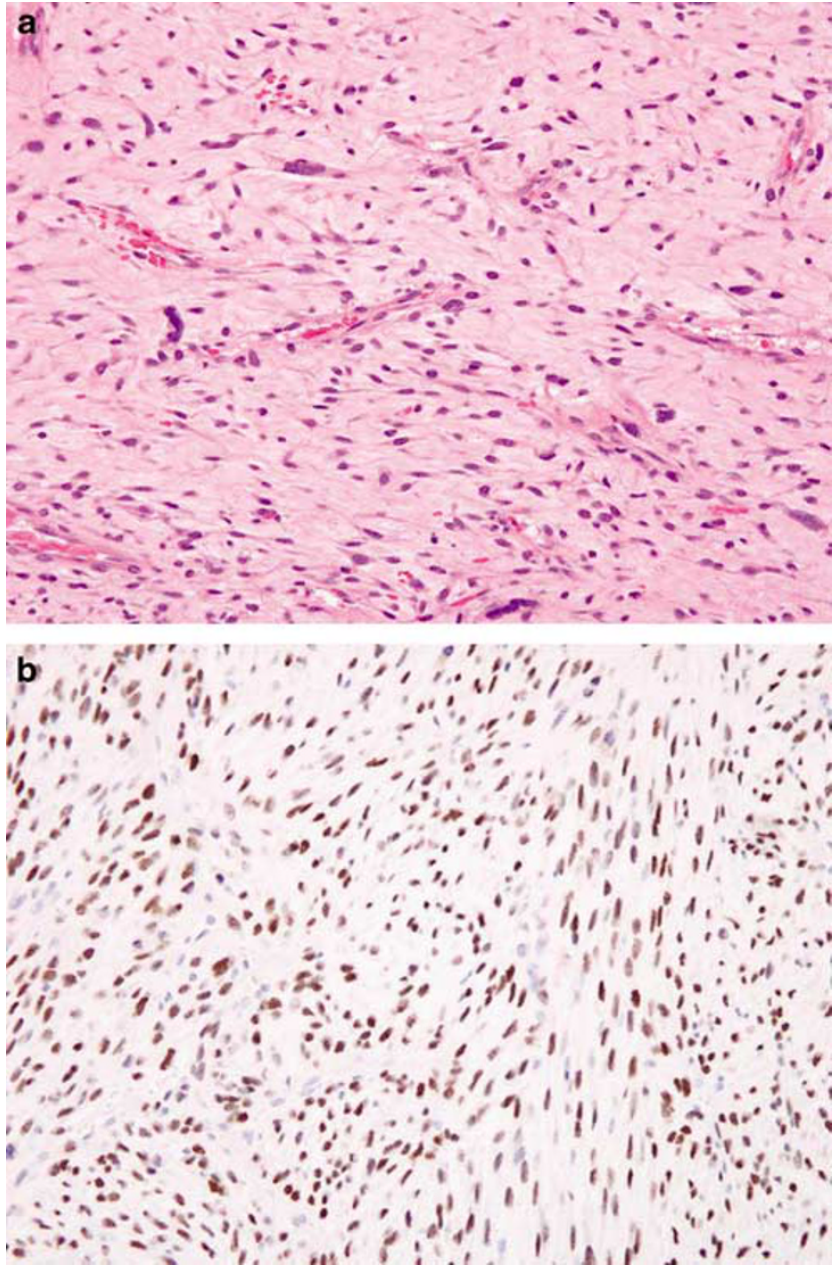

Figure 4 Myxoid and pleomorphic malignant peripheral nerve sheath tumor (a) with uniform $(3+)$ expression of TLE 1 (b).

more sensitive than the Ventana system utilized in this earlier study, a hypothesis we are unable to test.

Putting together our results with those of Terry et al, it would appear that TLE1 immunohistochemistry should have a somewhat limited role in the diagnosis of monophasic synovial sarcoma, as the differential diagnosis for synovial sarcoma includes a variety of other potentially TLE1-positive spindle cell tumors, most notably malignant peripheral nerve sheath tumor and solitary fibrous tumor. Certainly the finding of strong TLE1 expression in morphologically appropriate, CD34-negative spindle cell tumor with scattered cytokeratin-positive cells is strong evidence in favor of the diagnosis of synovial sarcoma (although in truth one might say the same even without testing such a tumor for TLE1). TLE1 might play a more valuable role in the distinction of poorly differentiated synovial sarcoma from other potentially cytokeratin-positive 'small blue round cell tumors', in particular Ewing sarco$\mathrm{ma} /$ primitive neuroectodermal tumor, ${ }^{17,18}$ and desmoplastic small round cell tumor, ${ }^{19}$ both of which do not appear to express TLE1 protein. Ultimately, 

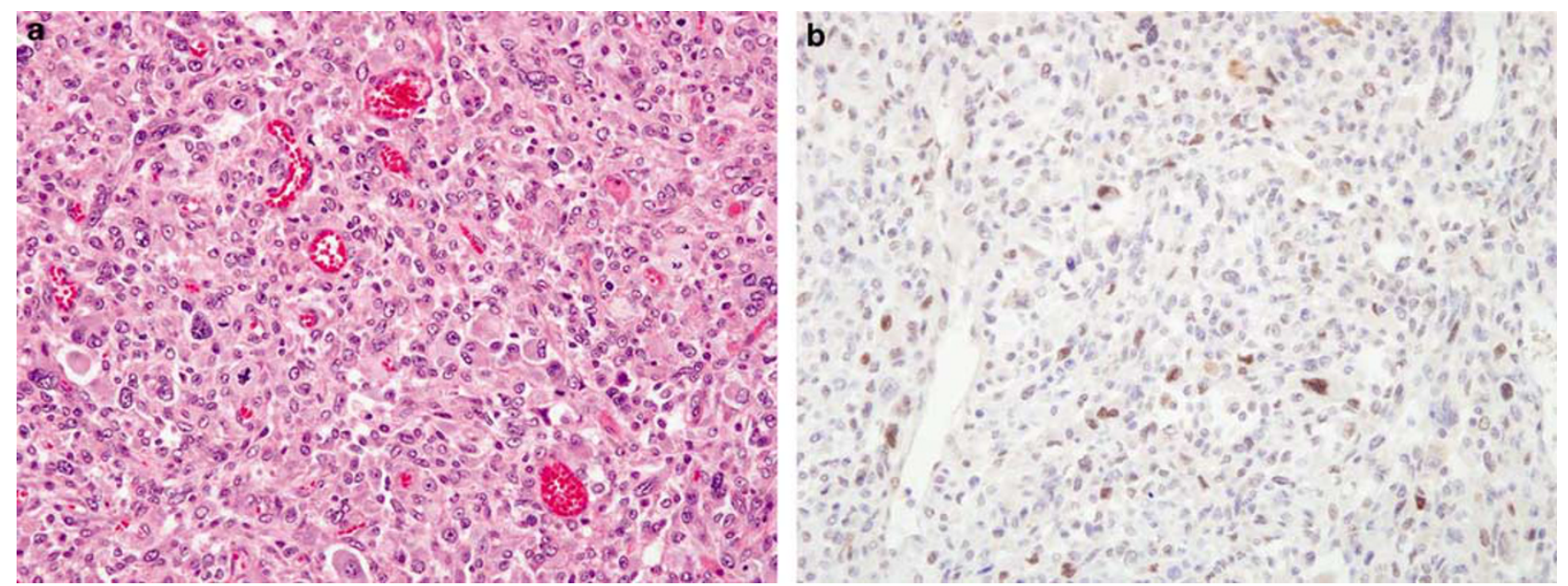

Figure 5 Pleomorphic malignant peripheral nerve sheath tumor (a), arising in a patient with neurofibromatosis type 1, with $2+$ TLE1 expression (b).
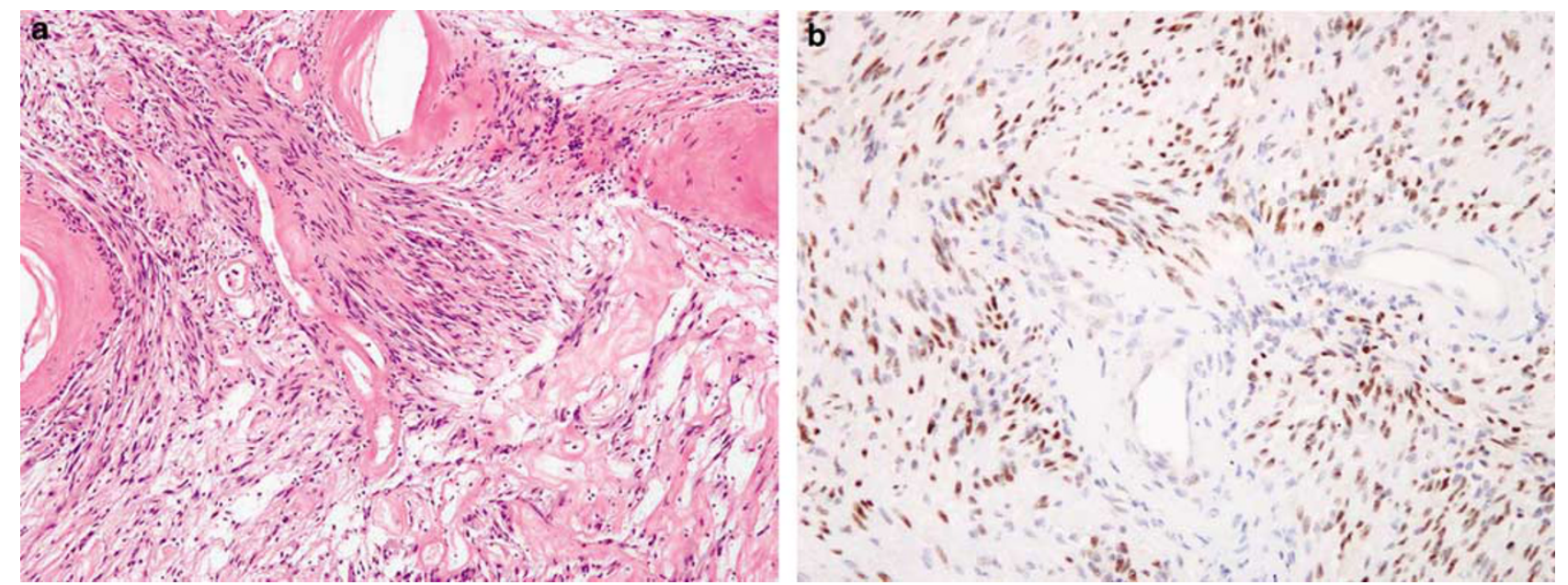

Figure 6 Schwannoma (a) with $3+$ TLE1 expression (b).
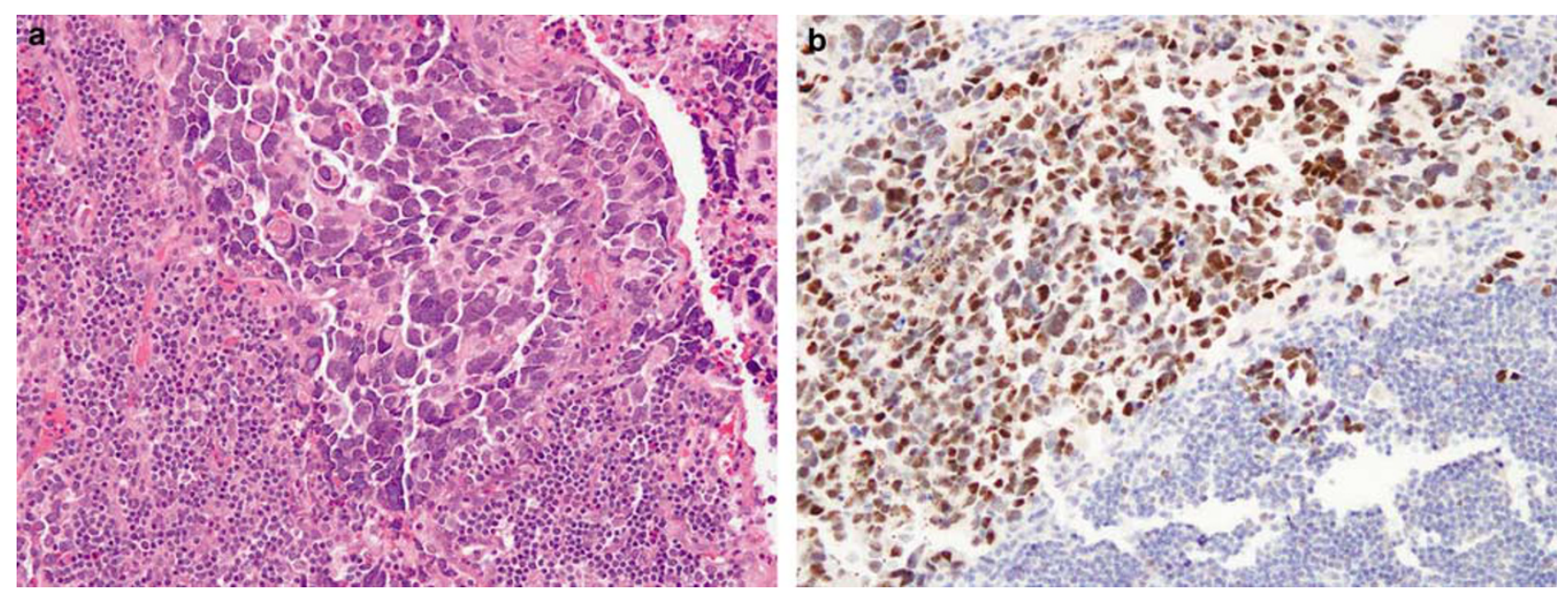

Figure 7 Alveolar rhabdomyosarcoma metastatic to a lymph node (a), with $3+$ TLE1 expression (b). 

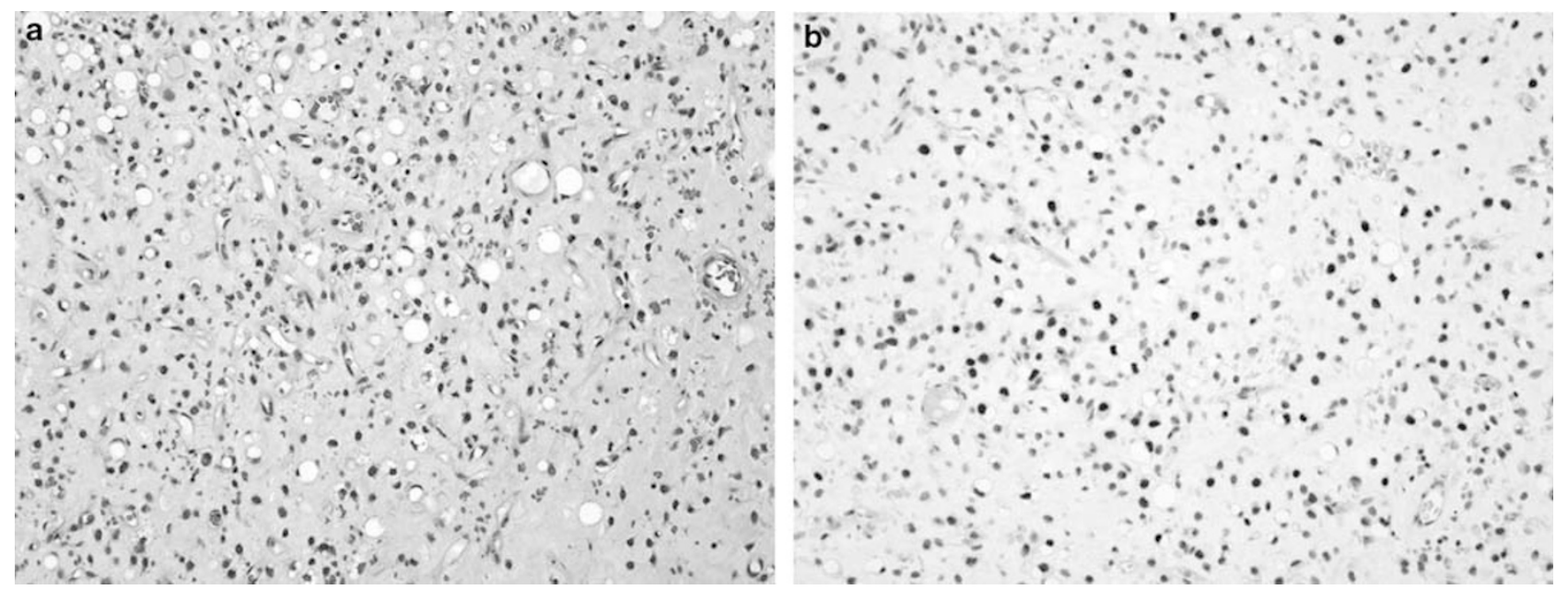

Figure 8 Low-grade myxoid liposarcoma (a) with $2+$ TLE1 expression (b).

however, it is difficult to see any advantage of TLE1 immunohistochemistry over RT-PCR or FISH detection of synovial sarcoma-specific genetic events (eg, $\mathrm{t}(\mathrm{X} ; 18)(S S 18-S S X 1-2)$, especially as such tests are available in an increasing number of laboratories, readily performed in formalin-fixed, paraffinembedded tissues, highly sensitive, and to date absolutely specific for the diagnosis of synovial sarcoma. ${ }^{20-26}$

In summary, using conventional whole tissue sections, we have identified strong TLE1 expression in the overwhelming majority of synovial sarcomas, as well as in a considerable number of other spindle cell tumors that may enter the differential diagnosis of synovial sarcoma. Although TLE1 immunohistochemistry may play a limited role in the diagnosis of synovial sarcoma when used in the context of a panel of morphology and traditional immunohistochemical markers, molecular confirmation of synovial sarcoma-associated fusion genes should remain the 'gold standard' for this diagnosis in problematic cases.

\section{References}

1 Weiss SW, Goldblum JR, Enzinger FM. Enzinger and Weiss' Soft Tissue Tumors. 5th edn. Mosby Elsevier: Philadelphia, PA, 2008.

2 Fletcher CDM, Unni KK, Mertens F, et al. Pathology and Genetics of Tumours of Soft Tissue and Bone. IARC Press: Lyon, 2002.

3 Folpe AL, Schmidt RA, Chapman D, et al. Poorly differentiated synovial sarcoma: immunohistochemical distinction from primitive neuroectodermal tumors and high-grade malignant peripheral nerve sheath tumors. Am J Surg Pathol 1998;22:673-682.

4 van de Rijn M, Barr FG, Xiong QB, et al. Poorly differentiated synovial sarcoma: an analysis of clinical, pathologic, and molecular genetic features. Am J Surg Pathol 1999;23:106-112.

5 Skytting B, Meis-Kindblom JM, Larsson O, et al. Synovial sarcoma-identification of favorable and unfavorable histologic types: a Scandinavian sarcoma group study of 104 cases. Acta Orthop Scand 1999; 70:543-554.

6 Liu Y, Dehni G, Purcell KJ, et al. Epithelial expression and chromosomal location of human TLE genes: implications for notch signaling and neoplasia. Genomics 1996;31:58-64.

7 Chen G, Courey AJ. Groucho/TLE family proteins and transcriptional repression. Gene 2000;249:1-16.

8 Stifani S, Blaumueller CM, Redhead NJ, et al. Human homologs of a Drosophila enhancer of split gene product define a novel family of nuclear proteins. Nat Genet 1992;2:119-127.

9 Daniels DL, Weis WI. Beta-catenin directly displaces Groucho/TLE repressors from Tcf/Lef in Wnt-mediated transcription activation. Nat Struct Mol Biol 2005; 12:364-371.

10 Brantjes H, Roose J, van De Wetering M, et al. All Tcf HMG box transcription factors interact with Grouchorelated co-repressors. Nucleic Acids Res 2001;29: 1410-1419.

11 Levanon D, Goldstein RE, Bernstein Y, et al. Transcriptional repression by AML1 and LEF-1 is mediated by the TLE/Groucho corepressors. Proc Natl Acad Sci USA 1998;95:11590-11595.

12 Pretto D, Barco R, Rivera J, et al. The synovial sarcoma translocation protein SYT-SSX2 recruits beta-catenin to the nucleus and associates with it in an active complex. Oncogene 2006;25:3661-3669.

13 Bozzi F, Ferrari A, Negri T, et al Molecular characterization of synovial sarcoma in children and adolescents: evidence of akt activation. Transl Oncol 2008; 1:95-101.

14 Baird K, Davis S, Antonescu CR, et al. Gene expression profiling of human sarcomas: insights into sarcoma biology. Cancer Res 2005;65:9226-9235.

15 Ng TL, Gown AM, Barry TS, et al. Nuclear beta-catenin in mesenchymal tumors. Mod Pathol 2005;18:68-74.

16 Terry J, Saito T, Subramanian S, et al. TLE1 as a diagnostic immunohistochemical marker for synovial sarcoma emerging from gene expression profiling studies. Am J Surg Pathol 2007;31:240-246.

17 Folpe AL, Goldblum JR, Rubin BP, et al. Morphologic and immunophenotypic diversity in Ewing family tumors: a study of 66 genetically confirmed cases. Am J Surg Pathol 2005;29:1025-1033. 
$18 \mathrm{Gu} \mathrm{M}$, Antonescu CR, Guiter G, et al. Cytokeratin immunoreactivity in Ewing's sarcoma: prevalence in 50 cases confirmed by molecular diagnostic studies. Am J Surg Pathol 2000;24:410-416.

19 Ordonez NG. Desmoplastic small round cell tumor: II: an ultrastructural and immunohistochemical study with emphasis on new immunohistochemical markers. Am J Surg Pathol 1998;22:1314-1327.

20 Surace C, Panagopoulos I, Palsson E, et al. A novel FISH assay for SS18-SSX fusion type in synovial sarcoma. Lab Invest 2004;84:1185-1192.

21 Li F, Li XX, Chang B, et al. [Diagnostic significance and clinical application of specific chimeric genes in soft tissue sarcomas by RT-PCR using paraffin-embedded tissues: a study of 103 specimens]. Zhonghua Yi Xue Za Zhi 2004;84:1518-1521.

22 Jin L, Majerus J, Oliveira A, et al. Detection of fusion gene transcripts in fresh-frozen and formalinfixed paraffin-embedded tissue sections of soft-tissue sarcomas after laser capture microdissection and rt-PCR. Diagn Mol Pathol 2003;12:224-230.

23 Liew MA, Coffin CM, Fletcher JA, et al. Peripheral nerve sheath tumors from patients with neurofibromatosis type 1 do not have the chromosomal translocation t(X;18). Pediatr Dev Pathol 2002;5:165-169.

24 Coindre JM, Hostein I, Benhattar J, et al. Malignant peripheral nerve sheath tumors are $t(X ; 18)$-negative sarcomas. Molecular analysis of 25 cases occurring in neurofibromatosis type 1 patients, using two different RT-PCR-based methods of detection. Mod Pathol 2002;15:589-592.

25 Ladanyi M. Fusions of the SYT and SSX genes in synovial sarcoma. Oncogene 2001;20:5755-5762.

26 Argani P, Zakowski MF, Klimstra DS, et al. Detection of the SYT-SSX chimeric RNA of synovial sarcoma in paraffin-embedded tissue and its application in problematic cases. Mod Pathol 1998;11: 65-71. 